CONF-8810155--10

DE89 002315

\title{
APPLICATION OF SIGNATURE ANALYSIS FOR DETERMINING \\ THE OPERATIONAL READINESS OF MOTOR-OPERATED \\ VALVES UNDER BLOWDOWN TEST CONDITIONS
}

H. D. Haynes

Oak Ridge National Laboratory

Oak Ridge, Tennessee 37831

For Publication in the Proceedings of the 16th Water Reactor Safety Information Meeting at the National Bureau of Standards, Gaithersburg, Maryland, October 24-27, 1988.

\footnotetext{
The submitted manuscript has bean authored by a contractor of the U.S. Covernment under contract No. DE-AC05-84OR21400. Accordingly, the U.S. Covernment retains a nonexclusive, royalty-free license to publizh or reproduce the published form of this contribution, or allow others to do s0, for U.S. Government purposes."
}

\section{DISCLAIMER}

This report was prepared as an account of work sponsored by an agency of the United States Government. Neither the Uuited States Government nor any agency thereof, nor any of their employees, makes any warranty, express or implied, or assumes any legal liability or responsibility for the accuracy, completeness, or usefulness of any information, apparatus, product, or process disclosed, or represents that its use would not infringe privately ow'ned rights. Reference herein to any specilic commercial product, process, or service by trade name, trademark. manufacturer, or otherwise does not necessarily constitute or imply its endorsement, recommendation, or favoring by the United States Government or any agency thereof. The views and opinions of authors expressed herein do not necessarily state or reflect those of the United States Government or azy agency thereof. 


\title{
APPLICATION OF SIGNATURE ANALYSIS FOR DETERMINING \\ THE OPERATIONAL READINESS OF MOTOR-OPERATED \\ VALVES UNDER BLOWDOWN TEST CONDITIONS*
}

\author{
H. D. Haynes \\ Oak Ridge National Laboratory \\ Oak Ridge, Tennessee
}

\begin{abstract}
In support of the NRC-funded Nuclear Plant Aging Research (NPAR) program, Oak Ridge National Laboratory (ORNL) has carried out a comprehensive aging assessment of Motor-Operated Valves (MOVs).

As part of this work, ORNL participated in the Gate Valve Flow Interruption Blowdown (GVFIB) tests carried out in Huntsville, Alabama. The GVFIB tests were intended primarily to determine the behavior of motor-operated gate valves under the temperature, pressure, and flow conditions expected to be experienced by isolation valves in Boiling Water Reactors (BWRs) during a high energy i ine break (blowdown) outside of containment. In addition, the tests provided an excellent opportunity to evaluate signature analysis methods for determining the operational readiness of the MOVs under those accident conditions.

ORNL acquired motor current and torque switch shaft angular position data on two test MOVs during various times of the GVFIB tests. The reduction in operating "margin" of both MOVs due to the presence of additional valve running loads imposed by high flow was clearly observed in motor current and torque switch angular position signatures. In addition, the effects of differential pressure, fluid temperature, and line voltage on MOV operations were observed and more clearly understood as a result of utilizing signature analysis techniques.
\end{abstract}

\section{INTRODUCTION AND OBJECTIVES}

Motor-operated valves (MOVs) are located in almost all nuclear power plant fluid systems. Their failures have resulted in significant maintenance

\footnotetext{
*Research sponsored by the Office of Nuclear Regulatory Researcin, U.S. Nuclear Regulatory Commission under Interagency Agreement DOE 0551-0551-A1 with the U.S. Department of Energy under contract DE-AC05-840R21400 with Martin Marietta Energy Systems, Inc.
} 
efforts and, on occasion, have lead to the loss of safety system operational readiness. Consequently, in recent years MOVs have received considerable attention by the Nuclear Regulatory Commission (NRC) and the nuclear power industry. As a result, Oak Ridge National Laboratory (ORNL) has carried out a comprehensive aging assessment of MOVs in support of the Nuclear Plant Aging Research (NPAR) program which was established by the Office of Nuclear Regulatory Research (RES), primarily as a means to resolve technical safety issues related to the aging of electrical and mechanical components, systems, and structures used in commercial nuclear power plants.

A primary objective of the NPAR program is to identify and recommend methods of inspection, surveillance, and monitoring that would provide timely detection of service wear (aging) affecting important components and systems so that maintenance or replacement can be performed prior to loss of safety function(s). In that regard, ORNL research has focused on the evaluation of potentially useful signature analysis methods for determining the operational readiness of MOVs. This work provides technical information applicable to the resolution of Generic Issue II.E.6.1 (In Situ Testing of Valves) as well as IE Bulletins and Information Notices such as IEB 85-03 (Motor Operated Valve Common Mode Failures During Plant Transients Due to Improper Switch Settings).

In support of the NPAR programmatic objectives, GRNL participated in the Gate Valve Flow Interruption Blowdown (GVFIB) tests sponsored by the NRC/RES Mechanical Qualification Program and carried out under subcontract to INEL by WYLE Laboratories in Huntsville, Alabama. The results of the GVFIB tests are described in a paper presented by INEL at the 16th Water Reactor Safety Information Meeting (1). The GVFIB tests were intended primarily to determine the behavior of motor-operated gate valves under the temperature, pressure, and flow conditions expected to be experienced by isolation valves in Boiling Water Reactors (BWRs) during a high energy line break (blowdown) outside of containment. In addition, the tests provided an excellent opportunity to evaluate signature analysis methods for determining the operational readiness of the MOVs under those accident conditions.

\section{BACKGROUND}

ORNL has, in the past, carried out research in order to identify the type and potential value of diagnostic information from many MOV measurable parameters. In the course of these investigations, it was discovered that the MOV's electric motor acted effectively as a transducer by directly converting variations in drive train mechanical loads into variations in motor current which were sensed remotely (at the motor control center) using a non-intrusive clamp-on current probe.

Further research led to the development of special signal conditioning electronics and motor-current signature analysis (MCSA) techniques which together provided a means of sensitively and selectively extracting motor- 
current signal information from the power line to reveal MOV performance indicators on many levels including:

- Mean values of running current levels during "no load", pre-unseating, and "mid-stroke" portions of a valve stroke

- Variations in running current levels (both large and small) which are associated with changes in mechanical running loads during a valve stroke

- Initiation time, duration, and magnitude of motor-current transients which are characteristic of momentary motor operator and valve events including operator hammerblow, valve seating, valve unseating, valve backseating, and unusual transient events

- Worm gear tooth meshing indications on a tooth-by-tooth basis

- Overall current noise level which is generally indicative of smooth or rough operations

- Individual frequency spectral peaks associated with periodic current modulations resulting from periodic load variations within the MOV drive train.

Motor current spectra, which are comparable to vibration spectra, comonly include worm gear tooth meshing, stem nut rotation, motor shaft speed, and motor slip frequencies. Harmonic and sideband frequencies are often observed which provide indications of eccentricity and/or wear.

In addition to motor current, the monitoring method assessments carried out by ORNL illustrated that the angular position of the MOV torque switch shaft could be monitored and used as a meaningful diagnostic signal as well. Since the angular position of the torque switch shaft primarily reflects the motor operator torque output which is transferred as stem thrust via the operator's stem nut, a measure of the instantaneous angular position of the torque switch shaft during a valve stroke provides a relative measure of the instantaneous valve stem thrust.

\section{SYSTEM DESCRIPTIONS}

The system utilized for the Gate Valve Flow Interruption Blowdown Test featured a large water tank which was pressurized by a nitrogen supply so that various system water pressuie conditions could be established and regulated. Water was heated by means of an electric heater section and was circulated through the system by a high-pressure, high-temperature pump. A motoroperated valve was positioned in the system such that it could be actuated during times when the valve contained pressurized, heated water.

Two different motor-operated valves were tested in this system:

Valve "A" - Anchor/Darling, 6-inch, 900 pound standard rated, flexwedge gate valye with a Limitorque SMB-2-40 motor operator

Valve "B" - Velan, 6-inch, 900 pound standard rated, flexwedge gate valve with a Limitorque SMB-0-25 motor operator 
Both MOVs utilized $460 \mathrm{VAC}, 3$ phase, $60 \mathrm{~Hz}$ electric motors. The motor operator used on valve "B" was sized in accordance with current practices, whereas the motor operator used by valve "A" was oversized, although its delivered torque was adjusted so that it did not damage the valve.

The system contained bleed valves which provided the means to reduce system pressure on both sides (upstream and downstream) of the test MOV. In this manner, differential pressure conditions were established across the MOV's obturator when the MOV was closed. The system also featured a fast acting, hydraulically operated valve which was positioned in the system downstream of the test MOV so that when actuated, the system's contained fluid was abruptly released externally resulting in a high flow (blowdown) condition through the MOV being tested. The test MOV was then actuated in the open-toclose direction during the blowdown in order to determine whether it could successfully close against the high energy event. System fluid pressure and temperature were varied for each blowdown. Several blowdowns were carried out on each MOV.

Before any blowdown tests were performed on a test MOV, a series of qualification bests and other pre-blowdown tests were carried out. The qualification tests included MOV actuations under various system fluid pressures, fluid temperatures, and motor line voltages. MOV actuations were carried out immediately prior to each full system blowdown at the same fluid pressure and temperature conditions as the blowdown but with no flow.

\section{EQUIPMENT USED AND SIGNATURE ANALYSIS TECHNIQUES}

ORNL acquired motor current and torque switch shaft angular position data for both test MOVs at various times throughout the GVFIB testing. The instrumentation used by ORNL is illustrated by Figure 1 .

MOV torque switch shaft position was measured by an angular displacement transducer (ADT) which was installed on the torque switch of both MOVs in a manner which allowed the switch compartment to be closed during the MOV tests. The ADT utilized by ORNL was a variable capacitance device which provided a $D C$ voltage output that varied linearly with the angular position of its shaft. The ADT provided high sensitivity (100 miv per degree of rotation), infinite resolution (analog output), and an insignificant load on the torque switch.

Motor-current monitoring was carried out using a clamp-on current transformer installed on a single motor lead at the MOV. Special signal conditioning electronics were used to transform raw current signals supplied by the current probe into two recordable signals: one optimized for time domain analyses and one optimized for analyses in the frequency domain.

Torque switch position and motor current signals were recorded in analog form by a high quality cassette data recorder. Analog signal recordings were 


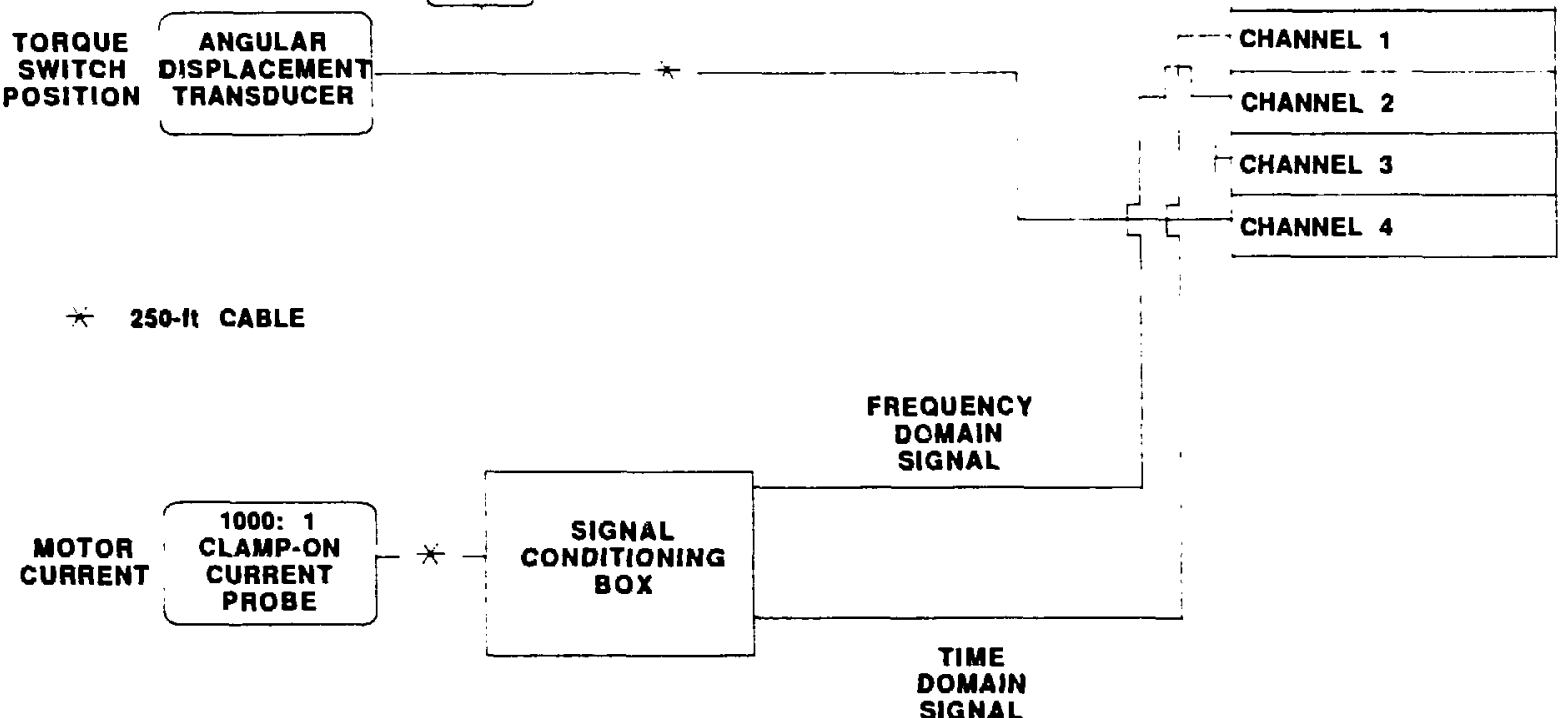

Fig. 1. GVFIB test instrumentation diagram.

made (rather than digital) so that time and frequency resolution of test data was not limited to an original digitization rate (as in direct digital recordings). Analog signal recordings were then post-digitized at whatever rate that was optimum for a particular analysis such as a MOV full-stroke waveform analysis using a relatively slow post-digitization rate or an analysis of seating and unseating transients where a higher post-digitization rate was desired.

In addition, time waveforms were produced after passing the recorded motor-current noise signals through a narrow frequency band filter. Ising this selective waveform inspection method (SWIM), unique motor current signatures were developed which reflected the time dependent amplitude modulations of the worm gear tooth meshing frequency. These waveforms display worm gear meshing on a tooth by tooth basis and, when transferred to a polar coordinate system, provided a means to detect worm gear meshing symmetries and asymmetries.

Another novel MCSA technique used was a method for determining whether an observed motor current level change was a result of a change in mechanical load or from a deviation in motor voltage without having to actually measure the motor voltage. This was accomplished by recognizing that an induction motor's slip (speed) and current are related by the motor's characteristic curve and voltage. Different slip vs. current relationships can occur for a given motor only at different voltages. In other words, when a higher or lower voltage condition existed during the time when motor current data acquisitions were performed, the slip/current relationship provided one method for detecting and quantifying the actual voltage. 
One of the initial observations made when analyzing motor-current signatures of valve "A" was that a general decrease in running current magnitudes occurred during the open-to-close stroke. This signature characteristic, along with the corresponding torque switch position signature, is shown in Figure 2. A drop in current of approximately 0.5 amps (5.75 to 5.25$)$ was seen in this MOV actuation which was carried out prior to the first system blowdown test.

Motor current and torque switch angular position signatures were then acquired during the first system blowdown (1000 psig, $480 \mathrm{~F}$ ) which occurred on $4 / 27 / 88$. As shown in Figure 3 , the previously observed decrease in motor running current was followed by a gradual increase in current as the valve was closed which reflected the additional running loads induced by the high velocity flow stream.

Near the end of the open-to-close stroke, a sudden increase in motor current and torque switch rotation was observed. This apparently ref lected a momentary misalignment between valve contacting surfaces prior to the gate establishing full sliding contact with the seat. Once this sliding contact was made, valve running loads decreased abruptly which identified the point in the valve stroke when the flow was completely blocked by the gate. This occurred approximately 1.6 seconds from the complete "bottoming out" of the gate which initiated a sudden and signiffcant rise in motor current and torque switch rotation which provided indications that the valve was fully seated.

Similar running load characteristics during the first blowdown valve closure were observed in the torque switch angular position signature, also
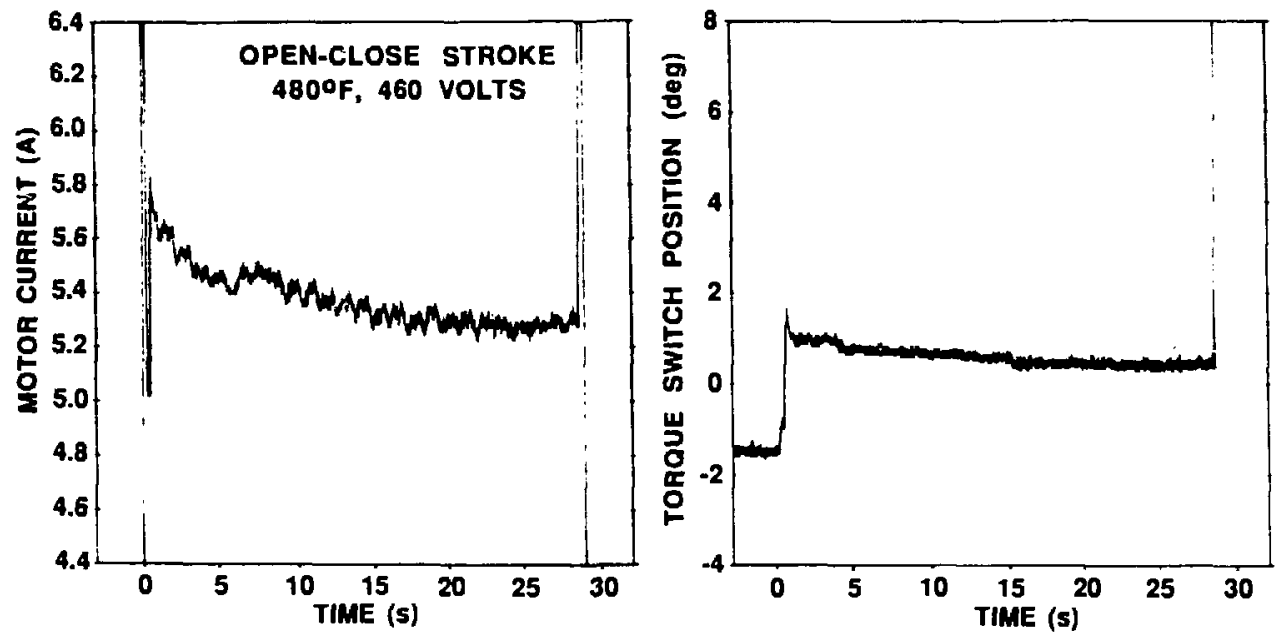

Fig. 2. Valve "A" - Typical signatures before blowdown (1000 psig, no flow). 

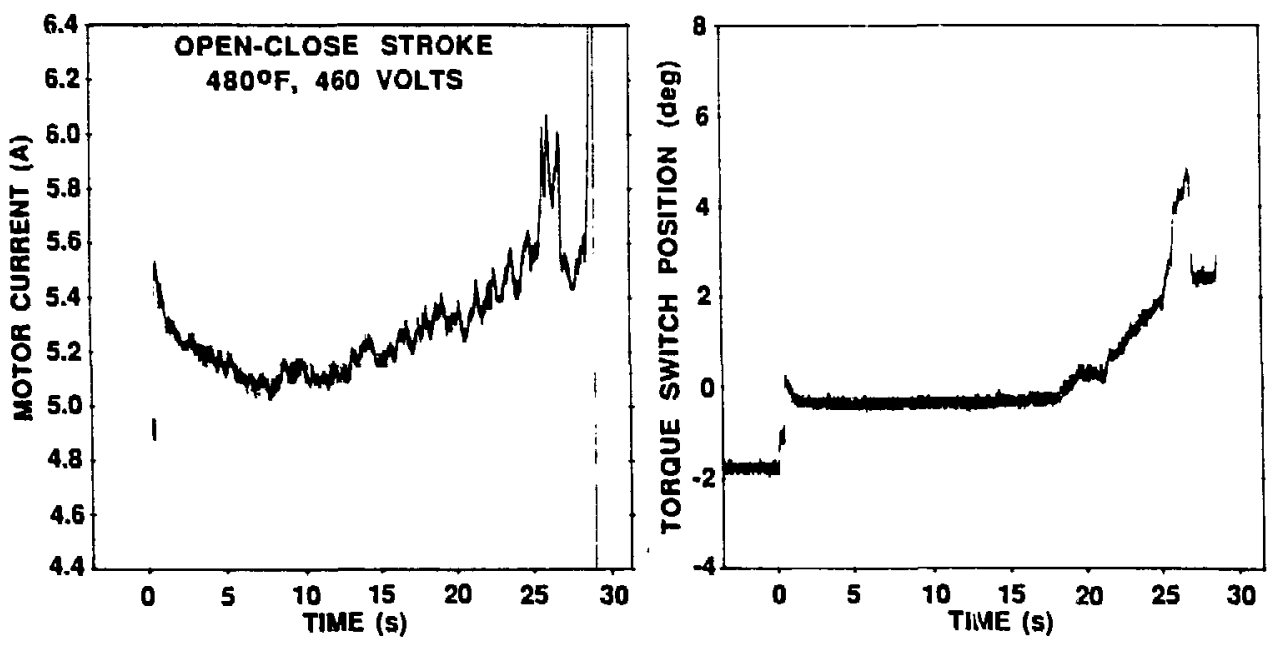

Fig. 3. Valve "A" - Signatures during first blowdown at 1000 psig (expanded vertical scale).

shown in Figure 3. One significant difference, however, should be noted. The torque switch position did not change during times when the valve running loads were below a level equivalent to 5.3 amps running current. This insensitivity to MOV running load variations below this point was apparently a reflection of springpack pre-load. A smal1 difference (approximately 0.67 degrees) was aiso observed between the "no-1oad" (after motor starts but before running loads are observed) and pre-load torque switch positions. This difference may have resulted from a small clearance between the torque switch drive gear and rack assembly.

As large as the blowdown pressure and flow effects appeared in Figure 3, their relative insignificance to the successful operation of the MOV was clear when comparing their magnitude to the magnitude of the final valve seating load as shown in Figure 4. The running loads from the first system blowdown were then expressed as a fraction of the total range between "no-load" and torque switch trip load as follows:

SIGNATURE

Motor current

Torque switch

Torque switch
MAXIMUM RUNEIING LOAD DURING FIRST BLOWDOWN

24.8\% of the difference between "no-load" current and the current at torque switch trip

23.7\% of the difference between "no-load" position and the position at torque switch trip

18.1\% of the difference between "no-load" position and the final position (including inertia) 

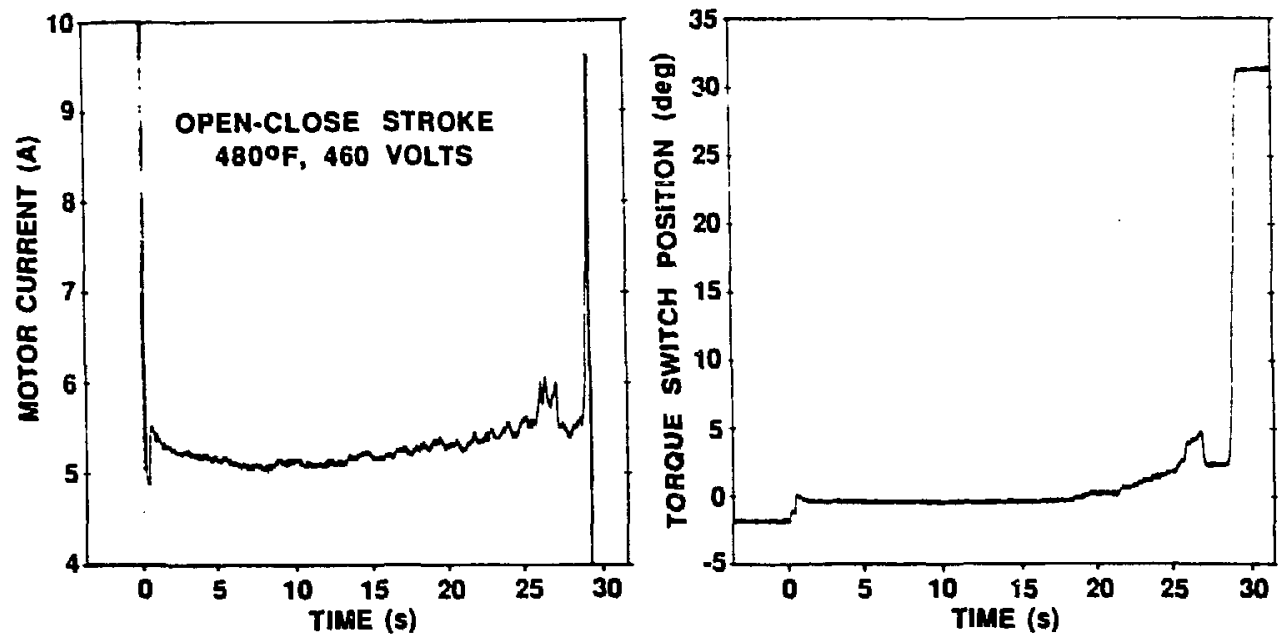

Fig. 4. Valve "A" - Signatures during first blowdown at 1000 psig (showing final values at torque switch trip).

Another way of visualizing the relative effects of blowdown pressure and flow on the closure of valve " $A$ " was by cross-plotting the motor current and torque switch angular position magnitudes as shown in Figure 5 . From this signature, the proximity of the running load magnitudes to the torque switch trip point is clearly seen as well as the additional inertial rotation of the torque switch after the motor tripped. The additional valve seating loads due to inertia were relatively large, as evidenced by the additional $32 \%$ in torque switch rotation after the motor shut off.

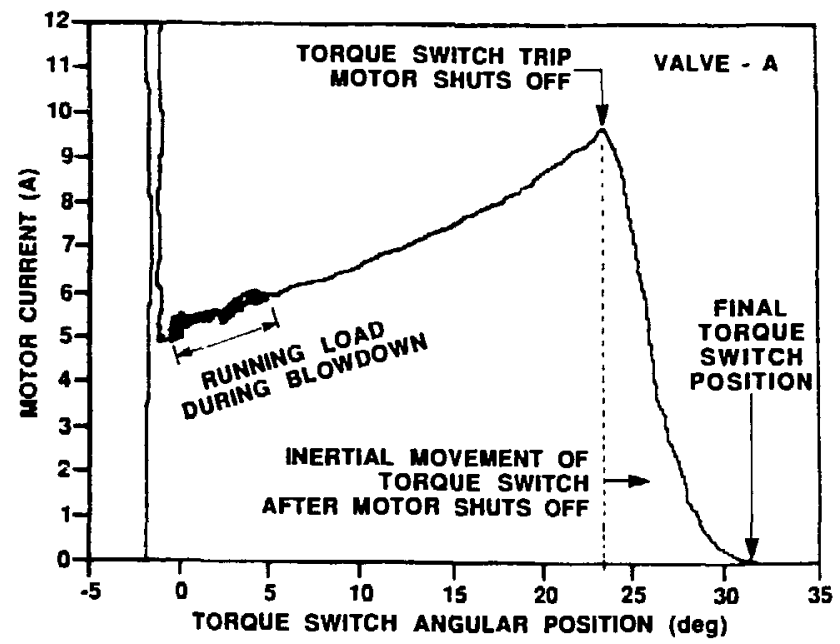

Fig. 5. Valve "A" - Motor current vs torque switch position during first blowdown. 
In addition to the blowdown test, motor current data were acquired for several valve "A" unseatings during a variety of initial differential pressure, fluid temperature, and line voltage conditions. It should be noted that during these valve openings against initial differential pressure, no fluid flowed thru the MOV other than that which led to an equalization of upstream and downstream pressures once the flow path was opened.

Figure 6 illustrates the effect of differential pressure and fluid temperature on valve "A" unseating using MCSA. In each signature two major motor current peaks are shown. The first represents motor operator hammerblow, the second peak reflects gate unseating.

As expected, when opened under no differential pressure, the MOV motor current signature indicated that no additional significant loads were present after gate unseating. However, when opened against 1700 pounds per sq.:are inch differential (psid) of cold water, the valve unseating peak was followed immediately by a period of increased running load which primarily reflected the differential pressure-induced disk guide friction which persisted until the flow path was opened and the pressures upstream and downstream of the MOV were allowed to equalize. The time measured from initial disk unseating to the point when the running load began to suddenly drop was 1.6 seconds. This
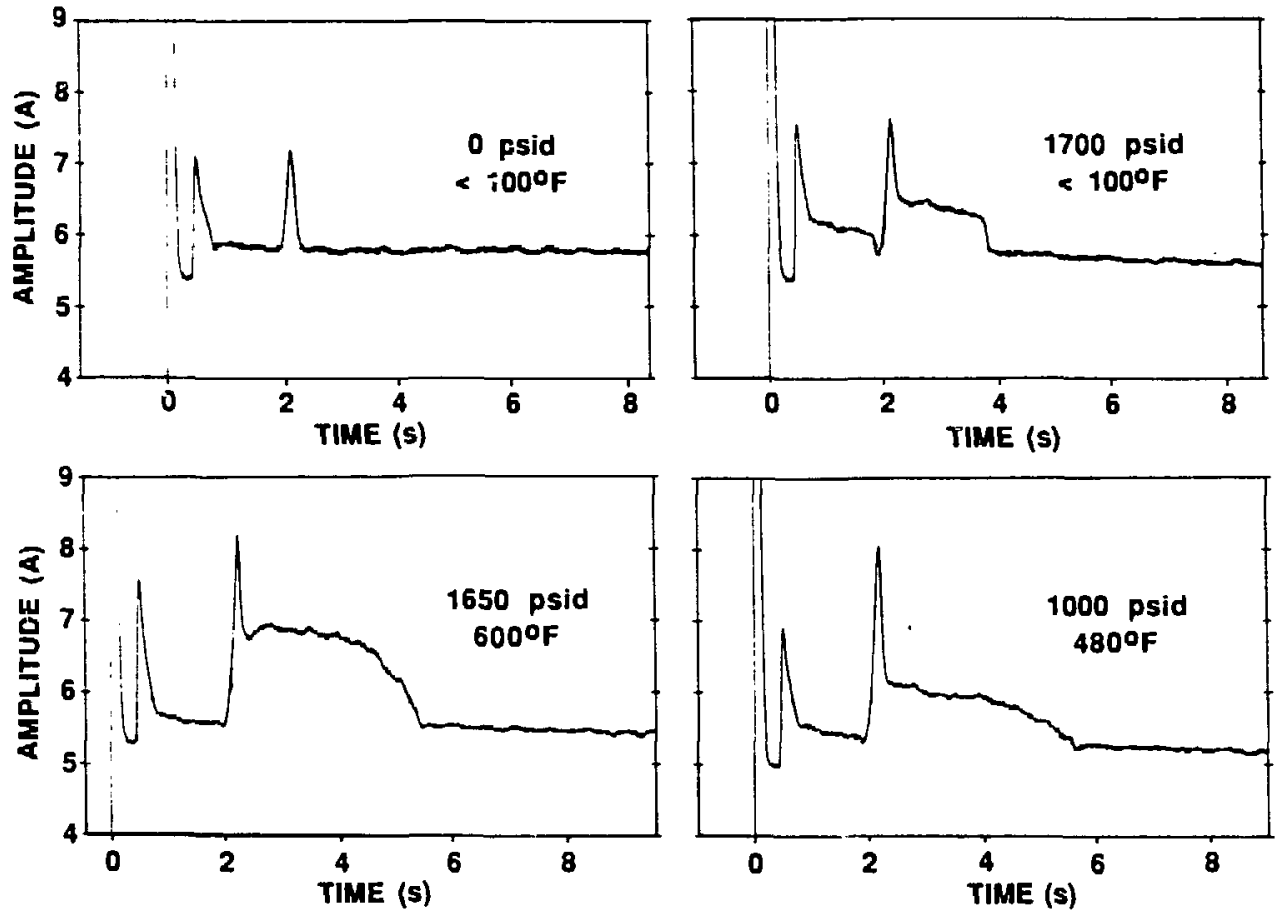

Fig. 6. Valve "A" - Effect of differential pressure and fluid temperature on gate valve unseating (460 volts). 
was the same time differential that was measured between the flow cutoff point and the point of initial gate/seat contact during the blowdown test and therefore reflected the same stem/gate travel. Once the flow path was opened, the pressure rapidly equalized in approximately 0.1 seconds as shown by the sudden decrease in the motor current magnitude.

When opened against $1650 \mathrm{psid}\left(600^{\circ} \mathrm{F}\right.$ water), and $1000 \mathrm{psid}\left(480^{\circ} \mathrm{F}\right.$ water), the times required for complete pressure equalization increased to approximately 1.6 seconds and 1.8 seconds, respectively. These times were determined by measuring the time differential between the point when the flow pach was first opened (1.6 seconds after the disk unseating transient) and the soint when the motor running current first stabilized fiolicating comp ate pressure equalization). The pressure equalization times were greater for the two hot water cases since the mass flow race of the flashing two phase (steam and water) mixture was lower (through the same sized valve opening) and thus required more time for the transfer of the mass of water necessary for the pressures upstream and downstream of the gate to equalize.

As expected, motor voltage was seen to be very influential on motor current signature characteristics as well. The effect of reduced voltage on the uiseating characteristics of valve "A" under 1650 psid $\left(600^{\circ} \mathrm{F}\right.$ water) initial conditions is illustrated by Figure 7 . The observed distortion in the motor current signature features at 368 VAC ( $80 \%$ of rated voltage) resulted from a shift in the motor characteristic response curve, which is more completely illustrated by the following motor current test data.

Motor slip (determined from the motor current frequency spectrum) and average motor running current (from time waveform ana7yses) were cross-plotted for valve "A" actuations under various pressure, flow, temperature, and
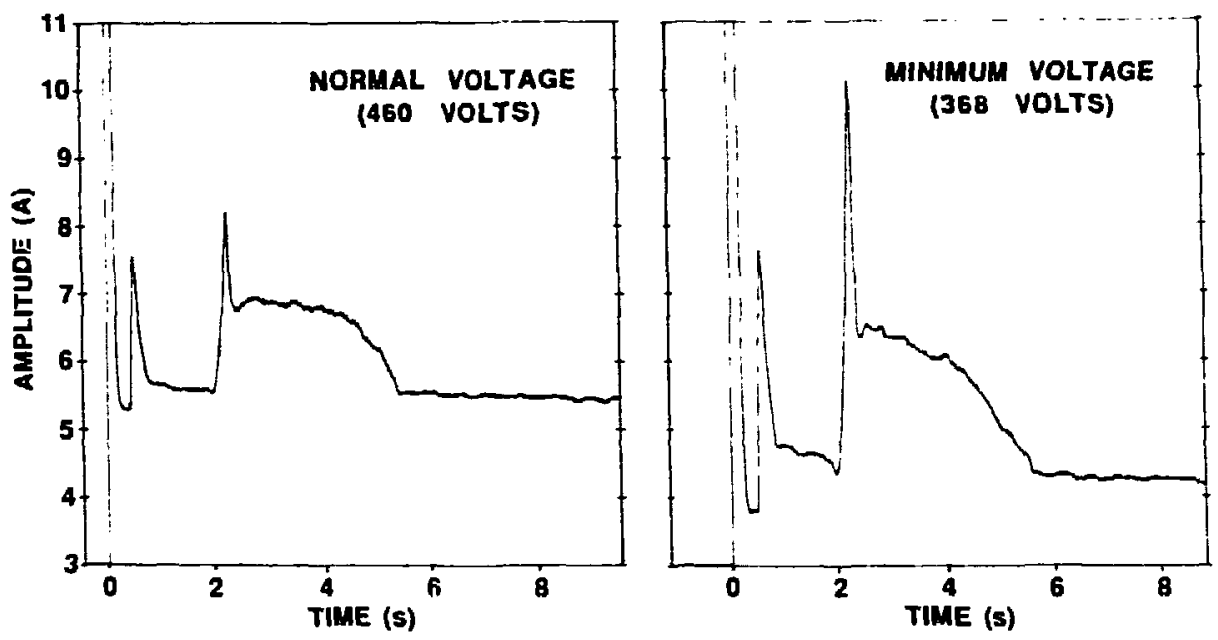

Fig. 7. Valve "A" - Effect of line voltage on gate valve unseating (1650 psid, $600^{\circ} \mathrm{F}$ ). 
voltage conditions. The slip/current relationship provided an indication of line voltage stability and was used in deteriaining if a change in motor running current was a result of a change in running load or from a line voltage deviation. Figure 8 illustrates that in addition to major changes seen between 368 VAC (80\%), 460 VAC (100\%), and 510 VAC (111\%) data sets, a relatively large amount of scalter was seen in the 460 VAC data. By a simple linear interpolation between the 460 VAC and 368 VAC data sets, a \pm 12 VAC variance was estimated for the 460 VAC data $( \pm 2.6 \%)$.

Further examinations of the 460 VAC slip/current data provided an indicatior that 1 apparent voltage variance was primarily due to data acquired on $4 / 27 / 88$ (the day of the first blowdown). Figure 9 shows that with the exception of the 8 data points which represented mov actuations on $4 / 27 / 88$ before the first blowdow, the remaining data (25 points) were contained in a relatively narrow band wich, using the above interpolation method, would account for an estimated voltage variation of only \pm 4 VAC (or $\pm 0.9 \%$ ). Since ORNL did not conitor cotor voltage during the GVFIB tests, the apparent voltage variations at 460 VAC identified by MCSA could not be verified.

On 5/24/88, a partial stroking of valve "A" was carried out while the blowdown echanisi (hydraulic valve) was kept in the open position. Hotor current and torque switch position signatures were acquired during a partial opening of the valve against blowdown flow which was iwnediately followed by a closure stroke. Figure 10 illustrates that, as expected, the flow-induced running loads were dependent on the position of the valve's obturator (gate) in the flow strean. In general, the greater the flow blockage was, the greater the flow-induced loads becane (as evidenced by the motor current and torque switch angular position signatures).

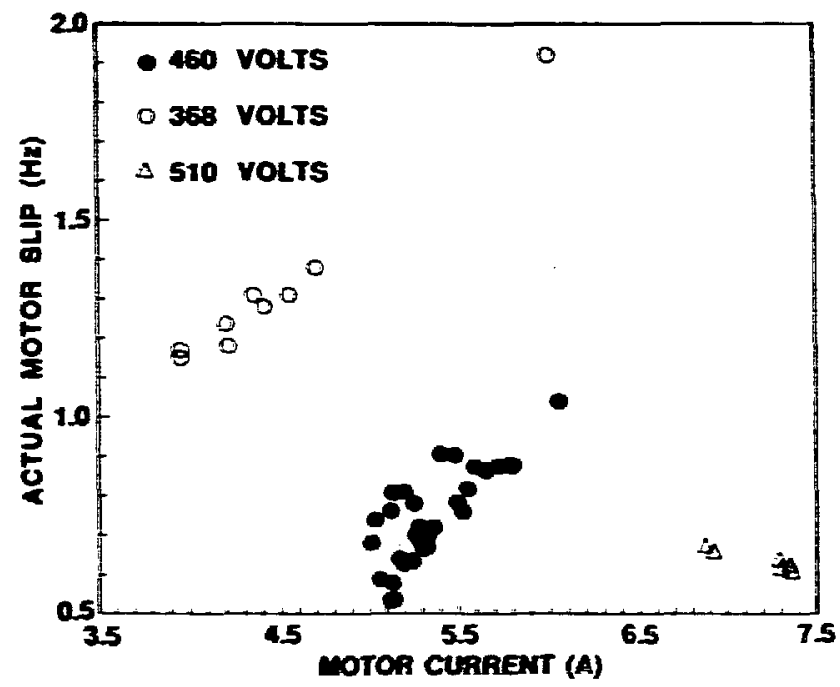

Fig. 8. Valve "A" - Motor characteristics from MCSA. 


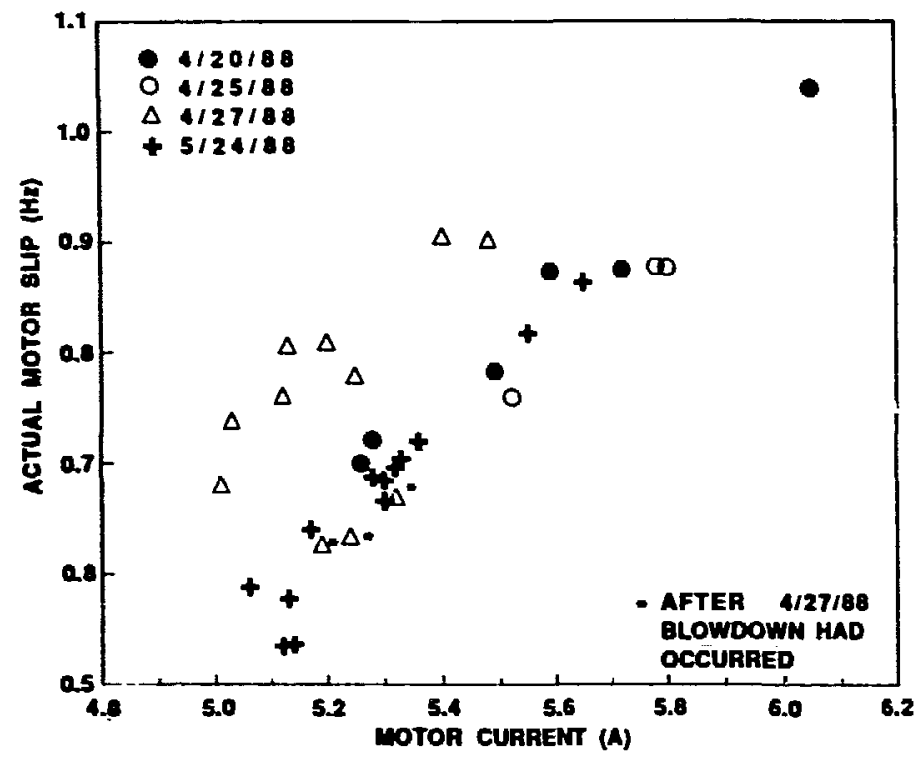

Fig. 9. Valve "A" - Motor characteristics at normal voltage (460 volts) from MCSA.
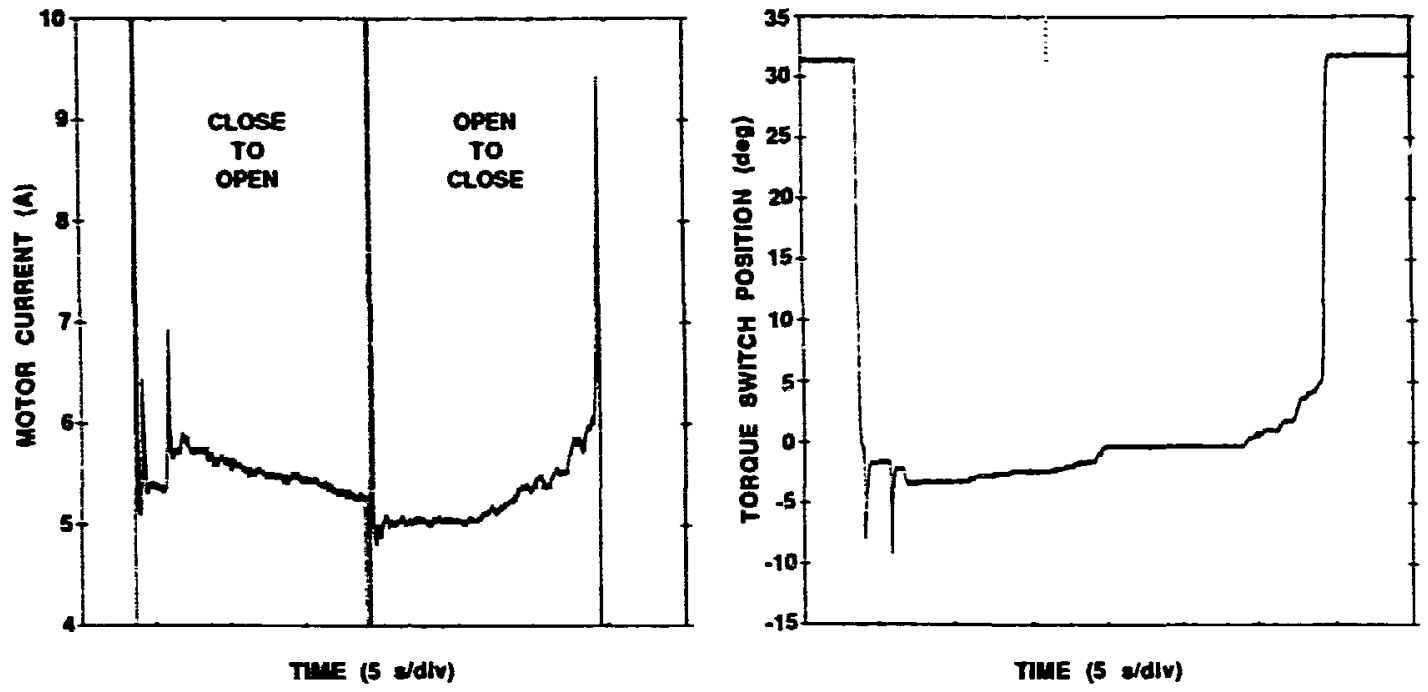

Fig. 10. Valve "A" - Partial opening and closing against blowdown flow (600 psig, $350^{\circ} \mathrm{F}, 460$ volts).

\section{TEST RESULTS - VALVE "B"}

Motor current and torque switch angular position signatures were acquired on valve " $B$ " during a system blowdown test which was carried out on $6 / 14 / 88$ at 
$1000 \mathrm{psig}$ and $530^{\circ} \mathrm{F}$. The effects of blowdown flow-induced valve loads were expected to be more noticeable on valve " $B$ " than on valve "A" primarily due to the size differences between their motor operators. Valve "B" used a smaller SMB- 0 operator and thus was more limited in its output than the larger SMB-2 operator used by valve "A".

Figures 11 and 12 illustrate the effect of the system blowdown on the closure of valve "B" as seen via motor current and torque switch position signatures, respectively. For comparison, signatures are also shown which were representative of an open-to-close stroke carried out prior to the blowdown at similar valve internal fluid pressure conditions but with no flow. An examination of these signatures indicated that the flow-induced valve running loads were so significant that they could have caused a torque switch trip pricr to valve gate/seat contact if they had been a little larger.

Maximum running loads during blowdown therefore represented a large fraction of the operating range of valve "B" as shown below:

SIGNATURE

Motor current

Torque switch

Torque switch
MAXIMUM RUNNING LOAD DURING BLOWDOWN

71.6\% of the difference between "no-load" current and the current at torque switch trip

87.3\% of the difference between "no-load" position and the position at torque switch trip

76.3\% of the difference between "no-load" position and the final position (including inertia)
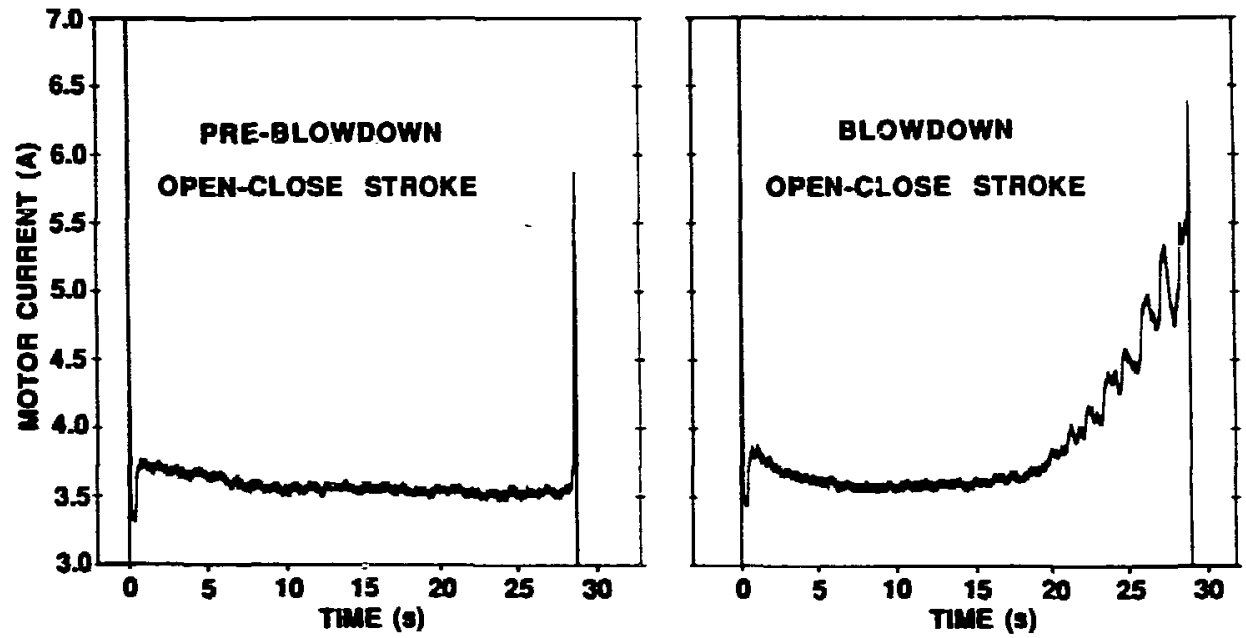

Fig. 11. Valve "B" - Effect of blowdown on motor current signature (1000 psig, $530^{\circ} \mathrm{F}, 460$ volts). 

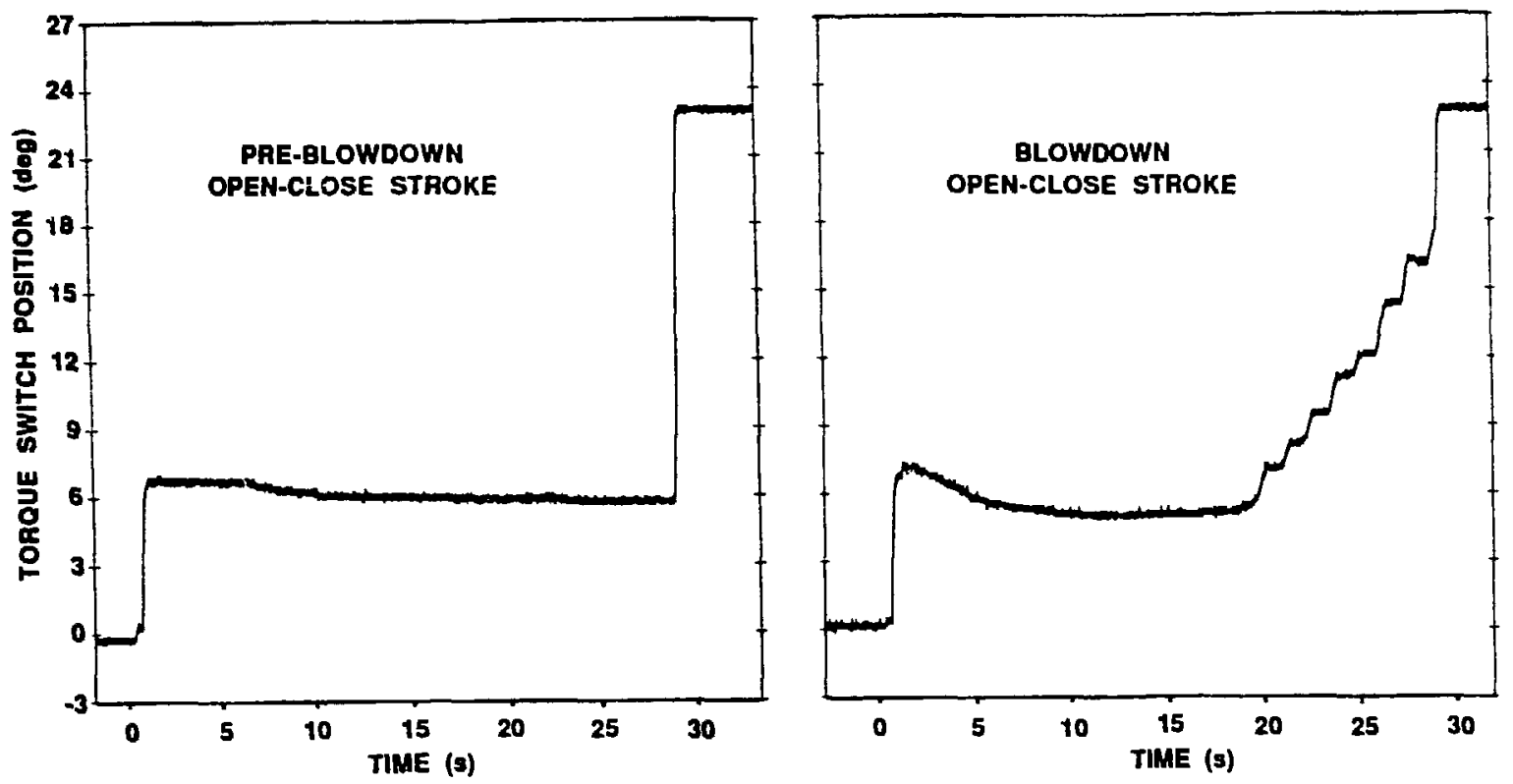

Fig. 12. Valve "B" - Effect of blowdown on torque switch position signature (1000 psig, $530^{\circ} \mathrm{F}, 460$ volts).

Motor current and torque switch position magnitudes were cross-plotted as shown by Figure 13 and clearly illustrate the reduction in vaive "B" operating margin due to the presence of flow-induced running loads. The close proximity of the maximum running load level to the torque switch trip point in the blowdown valve actuation indicated that after the valve gate contacted the seat, the torque switch rotated only a small amount (less than three degrees) before it tripped and shut off power to the motor. This small valve seating transient was also observed as a 0.8 anip motor current rise. For comparison, the torque switch and motor current signal rise during valve seating for the preblowdown (ro-flow) actuation were approximately 11.9 degrees and 2.15 amps, respectively.

In a manner similar to that previously performed on valve "A", a partial stroking of valve "B" was carried out while the blowdown mechanism (hydraulic valve) was kept in the open position. The motor current and torque switch position signatures acquired during this operation are illustrated by Figure 14 and are similar in many respects to those shown in Figure 10 (partial stroking of valve "A" against blowdown flow); however, one major difforence between the two signatures should be mentioned. The lack of an obvious valve unseating peak in Figure 14 reflected the lack of significant seating loads in the previous open-to-close stroke (see Figures 11, 12, and 13).

Once fluid was allowed to flow through the valve, an immediate increase in valve running loads were observed which subsequently decreased as the gate 

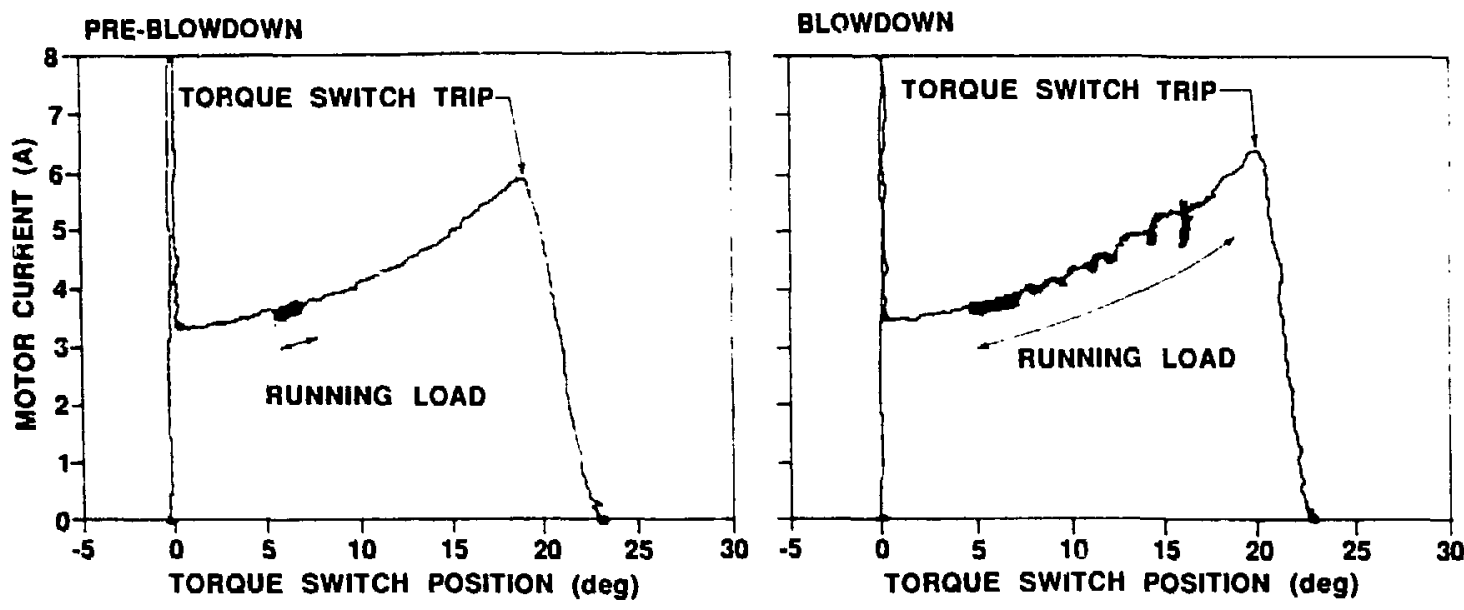

Fig. 13. Valve " $B$ " - Motor current vs torque switch position before and during blowdown $\left(1000 \mathrm{psig}, 530^{\circ} \mathrm{F}\right)$.
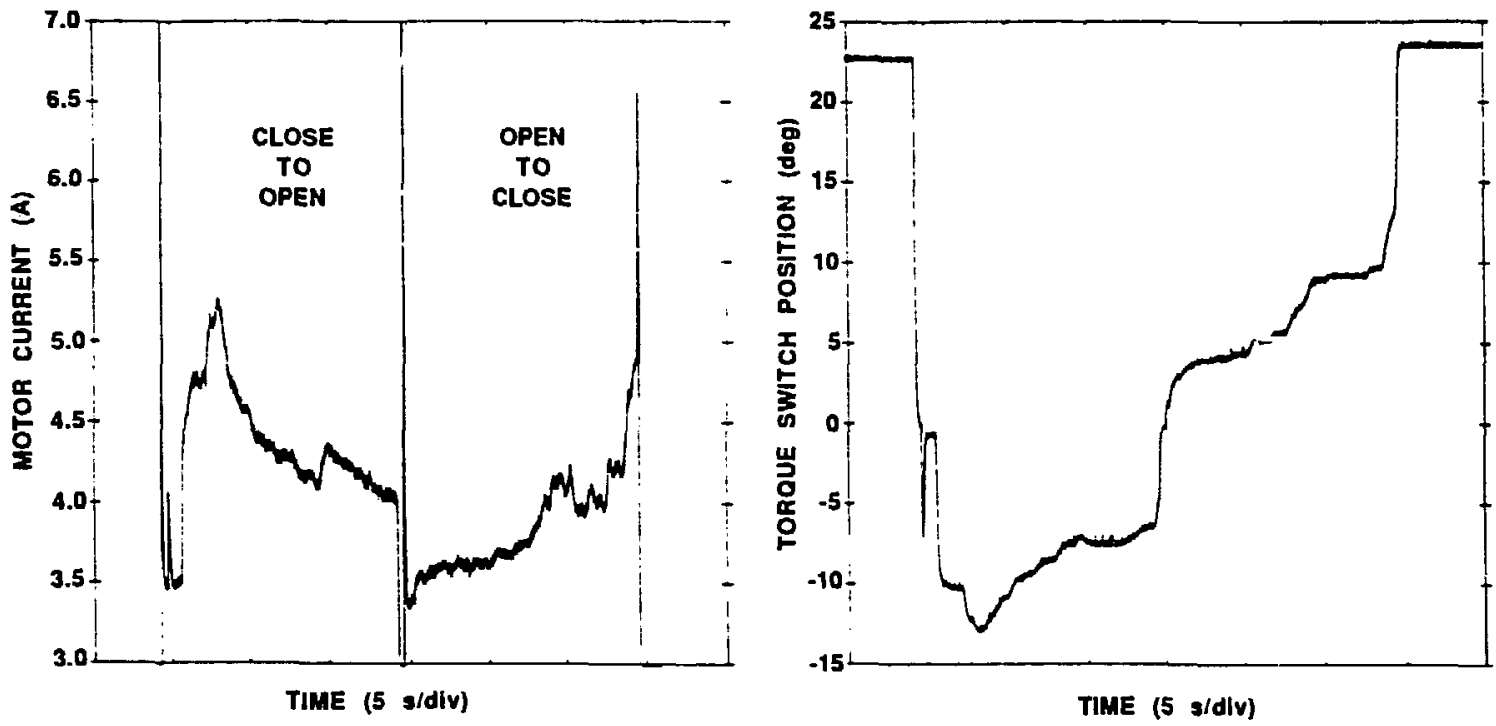

Fig. 14. Valve "B" - Partial opening and closing against blowdown flow (1000 psig, $350^{\circ} \mathrm{F}, 460$ volts).

was pulled out of the flow path. As the valve "B" gate was once again lowered into the high velocity flow, the valve running loads increased until the valve seated. It should be noted that valve running loads at gate/seat contact were not as large during this valve closure as seen in the full closure against blowdown flow (see Figure 11) due to the reduction in system fluid pressure which occurred between these two tests. Consequently, valve seating (gate-to- 
seat) loads were higher in this open-to-close stroke as evidenced by an increased motor current rise after gate/seat contact had been made.

Figures 15 and 16 are included in this paper primarily to illustrate additional MCSA techniques which, if utilized periodically, would be useful in identifying changes in internal operator characteristics and which may provide indicators of gear eccentricity and/or wear. Figure 15 shows a motor current noise signature obtained on valve " $B$ " which inclides spectral components at several known frequencies including motor speed and $s l i p$, worm gear rotation and worm gear tooth meshing. Amplitude modulations of the worm gear tooth meshing frequency, revealed using SWIM, are presented in Figure 16. The worm gear tooth meshing pattern shown in this figure provides indications that uneven worm gear tooth meshing loads were present at the time the motor current data were acquired, which may lead to uneven worm gear wear. No significant changes in motor current noise spectra or worm gear tooth meshing patterns were observed on either test MOV during the relatively short duration of the GVFIB tests. This suggested that no significant degradation had occurred within the motor operators as part of this test.

In summary, the Gate Valve Flow Interruption Blowdowr Test was an exce1lent opportunity for MOV diagnostic studies and more importantly, a means for
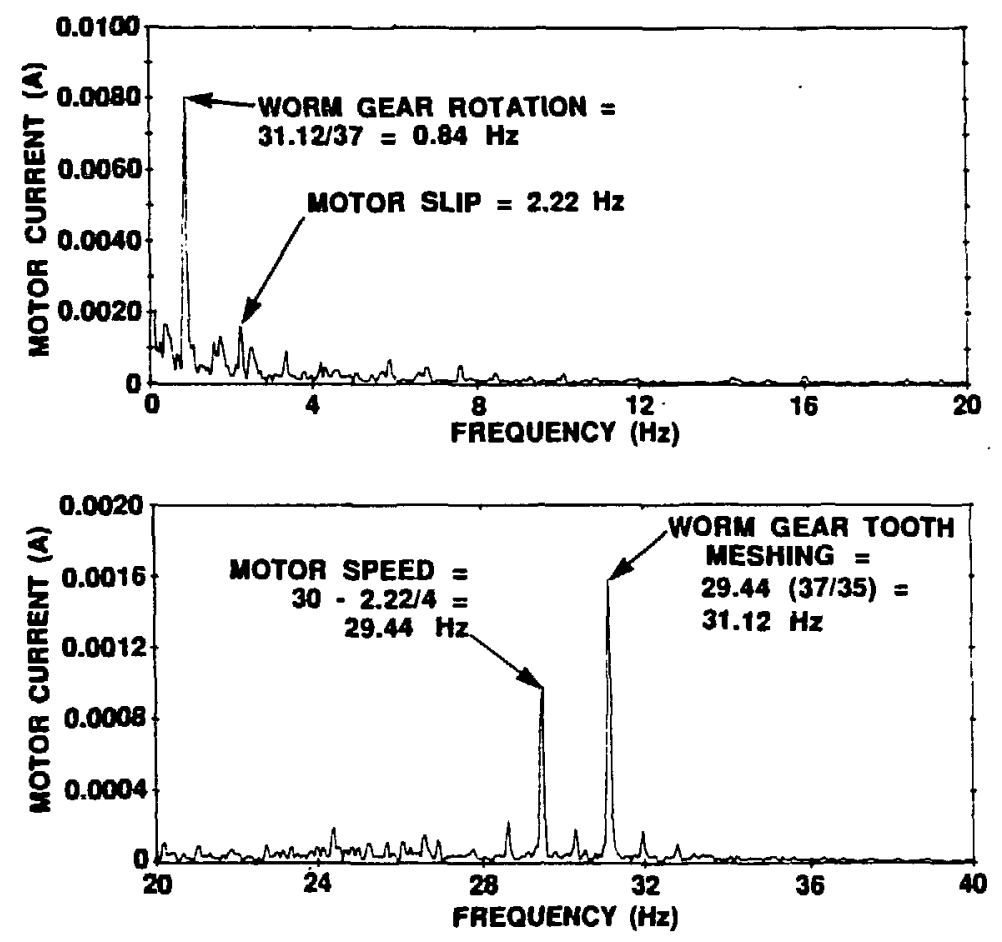

Fig. 15. Valve "B" - Typical motor current sjectrum (open-close stroke, 1000 psig, $530^{\circ} \mathrm{F}, 460$ volts). 


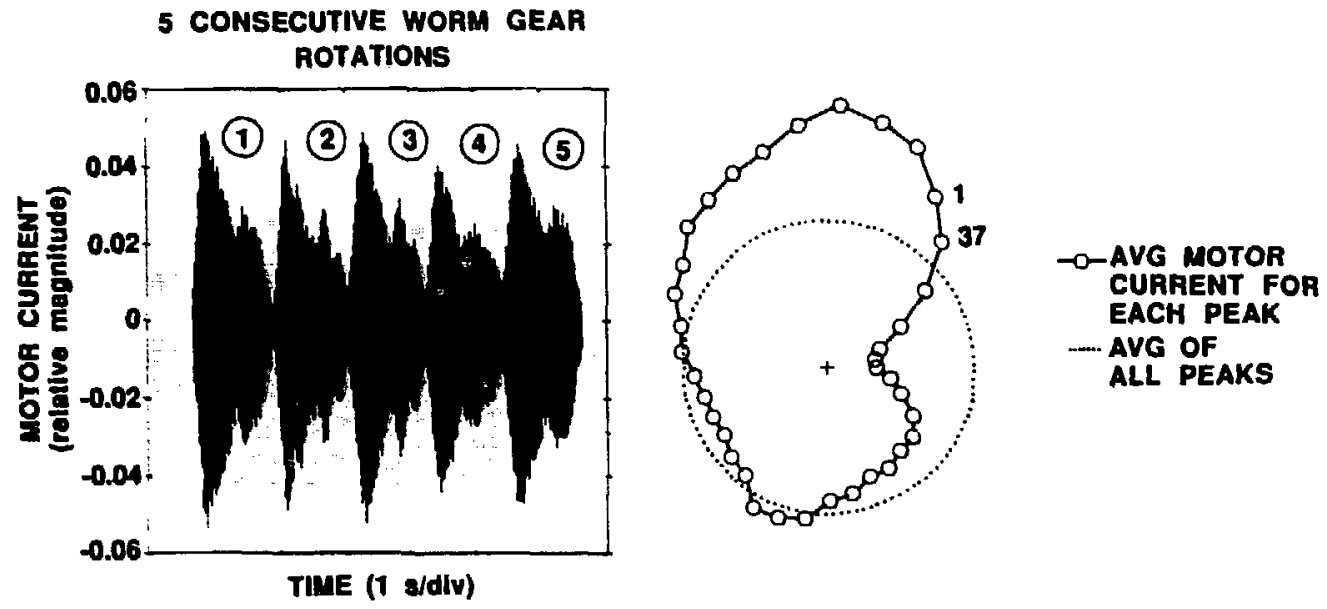

Fig. 16. Valve "B" - Typical worm gear tooth meshing pattern (open-close stroke, $1650 \mathrm{psig}, 600^{\circ} \mathrm{F}$ ).

determining the influences of high blowdown flow on the operation of BWR isolation valves. The reduction in operating "margin" of a motor-operated valve due to the presence of additional valve running loads imposed by high flow was clearly observed in motor current and torque switch angular position signatures. In addition, the effects of differential pressure, fluid temperature, and line voltage on MOV operations were observed and more clearly understood as a result of utilizing signature analysis techniques.

\section{REFERENCE}

1. K. G. DeWa11, Idaho National Engineering Laboratory, "Results of Gate Valve Flow Interruption Blowdown Tests," presented at the 16th Water Reactor Safety Information Meeting, Gaithersburg, Maryland, October 24-27, 1988. 